\title{
Development and Characterization of Microsatellite Markers in Citrus
}

\author{
Riaz Ahmad, Darush Struss, and Stephen M. Southwick ${ }^{1}$ \\ Pomology Department, University of California, Davis, CA 95616
}

\begin{abstract}
ADDITIONAL INDEX wORDS. molecular markers, SSR, DNA finger printing, cultivar identification
Abstract. We evaluated the potential of microsatellite markers for use in Citrus genome analysis. Microsatellite loci were identified by screening enriched and nonenriched libraries developed from 'Washington Navel' Citrus. Microsatellite-containing clones were sequenced and 26 specific PCR primers were selected for cross-species amplification and identification of cultivars/clones in Citrus. After an enrichment procedure, on average $69.9 \%$ of clones contained dinucleotide repeats $(\mathrm{CA}) \mathrm{n}$ and $(\mathrm{CT}) \mathrm{n}$, in contrast to $<25 \%$ of the clones that were identified as positive in hybridization screening of a nonenriched library. A library enriched for trinucleotide (CTT)n contained $<15 \%$ of the clones with (CTT)n repeats. Repeat length for most of the dinucleotide microsatellites was in the range of 10 to 30 units. We observed that enrichment procedure pulled out more of the (CA)n repeats than (CT)n repeats from the Citrus genome. All microsatellites were polymorphic except one. No correlation was observed between the number of alleles and the number of microsatellite repeats. In total, 118 putative alleles were detected using 26 primer pairs. The number of putative alleles per primer pair ranged from one to nine with an average of 4.5. Microsatellite markers discriminated sweet oranges [Citrus sinensis (L.) osb], mandarin (Citrus reticulata Blanco), grapefruit (Citrus paradisi Macf.), lemon [Citrus limon (L.) Burm.f.], and citrange (hybrids of trifoliate orange and sweet orange), at the species level, but individual cultivars/clones within sweet oranges, mandarins and grapefruit known to have evolved by somatic mutation remained undistinguishable. Since these microsatellite markers were conserved within different Citrus species, they could be used for linkage mapping, evolutionary and taxonomic study in Citrus.
\end{abstract}

The genus Citrus is diverse in species, cultivars and clones. Citrus sinensis (L.) Osbeck, sweet orange, is the main evergreen fruit-crop species, responsible for $75 \%$ of citrus production (Spiegel-Roy and Goldschmidt, 1996). Nearly all cultivars have arisen by somatic mutation in this group. The genetic variation in the mandarin group $($ C.reticulata $)$ is associated with sexual hybridization among a great number of species and intraspecific hybrids. Somatic mutations account for additional diversity within groups of cultivars, such as 'Satsuma' and 'Clementine' (Cameron and Frost, 1968). The presence of nucellar embryony coupled with high heterozygosity and long generation time has complicated Citrus breeding by conventional methods.

Molecular markers which are stable, detectable in all tissues, and independent of environmental conditions or production practices, have been used in Citrus in a wide range of applications including cultivar identification (Coletta et al., 1998; Fang and Roose, 1997), phylogenetics (Federici et al., 1998) and the construction of linkage maps (Kijas et al., 1997; Ling et al., 2000) for marker assisted breeding and map-based cloning of genes. One of the most reliable molecular marker systems is microsatellites or simple sequence repeats (SSRs), which are abundant and well distributed throughout the nuclear genomes of eukaryotes. These are generally present in noncoding DNA, which can accumulate mutations more easily than the coding DNA. Simple sequence length polymorphism (SSLP), caused by variation in the number of repeat units, can be easily detected by PCR using pairs of primers designed from unique sequences bordering the SSR motifs. These markers are highly polymorphic, multiallelic, and codominant and have proven useful for a variety

Received for publication 23 July 2002. Accepted for publication 4 Mar. 2003 The authors wish to thank Micheal Roose for providing Citrus samples DNA and Kevin Olsen and Roger Smith for leaf samples used in the present analysis. We are also thankful to Micheal Roose, Claire Federici, and Dan Potter for review of the manuscript. This work was supported by The California Citrus Research Board and the California Citrus Nursery Advisory Board.

${ }^{1}$ To whom correspondence should be addressed. of purposes including finger-printing (Smith and Devey, 1994), cultivar identification and genetic mapping (Guilford et al., 1997; Kijas et al., 1997), studying population genetics (Haymer, 1994), and differentiating between closely related genotypes (Smulders et al., 1997). Microsatellite loci developed from genomic DNA libraries tend to map randomly throughout the genome and are suitable for comparative genetic studies.

Microsatellites have been recognized as a good source of genetic markers in Citrus (Akkaya et al., 1992; Kijas et al., 1995; $\mathrm{Wu}$ and Tanksley, 1993), but a major limitation of SSRs is the time and cost required to isolate and characterize each locus when a pre-existing DNA sequence is not available. In Citrus, sufficient sequence data are not available in the database for designing microsatellite primers for analysis. Lengthy cloning and plasmid screening procedures are needed to identify candidate markers. In the present work, we used an enrichment and a nonenrichment protocol to isolate two classes of dinucleotide repeats (CT/GA and CA/GT) and trinucleotide repeat (CTT/GAA)n and established their presence, abundance and characteristics in the citrus genome. These SSR markers were used for cross species amplification and for identification and characterization of closely related cultivars/clones in sweet oranges (Citrus sinensis), mandarin (Citrus reticulata) and grapefruit (Citrus paradisi) which are believed to have evolved through mutation.

\section{Material and Methods}

Plant material. Microsatellite analyses were performed on 54 Citrus cultivars or clones representing different species (Table 1). Eleven samples of 'Parent Washington Navel' collected from different locations were also included in the analyses to find any possible variation in these samples as observed in inter-simple sequence repeat study by Fang and Roose, (1997). Mikeal Roose, University of California, Riverside, provided genomic DNA for 60 samples. Additional citrus leaf samples were collected from local nurseries and genomic DNA was extracted by DNeasy 
Table 1. Citrus cultivar/clones evaluated with 26 microsatellites.

\begin{tabular}{|c|c|}
\hline Navel Oranges [C. sinensis (L.) Osbeck] & Moro Blood Orange (C. sinensis) \\
\hline Atwood & Grapefruit (C. paradisi Macf.) \\
\hline Autumn Gold & Flame \\
\hline Barnfield & Red blush \\
\hline Cara Cara Pink & Rio Red \\
\hline Carter (old line) & Star Ruby \\
\hline Chislett (late) & Lemon [C. limon (L.) Burm.f.] \\
\hline Eddy (old line) & Lisbon \\
\hline Fisher (old line) & Mandarins (C. reticulata Blanco ) \\
\hline Frost nucellar & Algerian Clementine \\
\hline Fukumoto & Monreal Clementine \\
\hline Gillette (old line) & Caffin Clementine \\
\hline Lane Late & Clemenula Clementine \\
\hline Navelate (late) & Corsica\#1Clementine \\
\hline Navelina & Fina 3999 Clementine \\
\hline Newhall (old line) & Fina 4011Clementine \\
\hline Parent Washington at Lindcove* & Marisol Clementine \\
\hline Parent Washington at UCR* & Sidi Aissa Clementine \\
\hline Parent Washington (Historic) * & Fina Sodea Clementine \\
\hline Parent Washington at Lindcove* & Oroval Clementine \\
\hline Parent Washington at Lindcove* & W.Murcott \\
\hline Parent Washington at Lindcove* & Satsuma Mandarin (C. unshiu) \\
\hline Parent Washington at Lindcove* & Dobashi Beni Satsuma \\
\hline Parent Washington Mulholland Nursery 1993* & Frost Owari Satsuma \\
\hline Parent Washington Mulholland Nursery $1965^{*}$ & Kawano Wase Satsuma \\
\hline Parent Washington Mulholland Nursery $1972 *$ & Nepolitana Satsuma \\
\hline Parent Washington $\mathrm{Z}$ citrus nursery* & Hybrids \\
\hline Powell (Late) & Citranges $(C$. sinensis $\mathrm{x}$ Poncirus $)$ \\
\hline Rocky Hill (Old Line) & Carrizo \\
\hline Summer Gold (Late) & Troyer \\
\hline Thomson (sheldon) & Oroblanco (C. paradisi $\times$ C. grandis $)$ \\
\hline Valencia oranges $(C$. sinensis $)$ & Minneola Tangelo $(C$. paradisi $\times C$. reticulata $)$ \\
\hline \multicolumn{2}{|l|}{ Campbell (Old line) } \\
\hline \multicolumn{2}{|l|}{ Cutter nucellar } \\
\hline \multicolumn{2}{|l|}{ Frost nucellar } \\
\hline \multicolumn{2}{|l|}{ Delta } \\
\hline \multicolumn{2}{|l|}{ Midknight } \\
\hline \multicolumn{2}{|l|}{ Olinda nucellar } \\
\hline \multicolumn{2}{|l|}{ Olinda (old line) } \\
\hline Olinda & \\
\hline
\end{tabular}

Plant mini kit (Qiagen, Valencia, Calif. USA) following the manufacturer's protocol.

NONENRICHED LIBRARY CONSTRUCTION. Identification of microsatellites from the nonenriched library was performed according to Struss and Plieske (1998). A phage library was constructed from genomic DNA of 'Washington Navel' citrus by complete digestion of the DNA with the methylation sensitive restriction enzyme Pst1. The low molecular weight fraction was isolated from an agarose gel, digested with Mbo 1 and cloned into the Bam H1 site of the phage vector Zap express (Stratagene, La Jolla, Calif., USA). The library was screened for the presence of repeats by hybridization with $(\mathrm{GA})_{10}$ and $(\mathrm{GT})_{10}$ probes, labeled by random priming with ${ }^{32} \mathrm{P} \mathrm{CTP}$ (Feinberg and Vogelstein, 1983). Positive plaques were isolated and used to transfect Escherichia coli strain XL1 blue. The colonies were again hybridized with $(\mathrm{GA})_{10}$ and $(\mathrm{GT})_{10}$ probes and positive clones were sequenced.

ENRICHED LIBRARY CONSTRUCTION. To improve the efficiency of microsatellite isolation an enriched library was developed using the protocol of Hamilton et al. (1999) with some modifications as outlined below.

DNA PREPARATION.Genomic DNA was extracted from young leaves of citrus cultivar 'Washington Navel' by Plant DNeasy maxi prep (Qiagen) according to the manufacturer's protocol. About $15 \mu \mathrm{g}$ of genomic DNA was digested at $37^{\circ} \mathrm{C}$ overnight with restriction enzymes Rsa1 and Nhe1, which produced DNA fragments in the range of 300 to $800 \mathrm{bp}$. These DNA fragments were cleaned with a Qia Quick DNA purification columns (Qiagen) with $50 \mu \mathrm{L}$ final elution. Dephosphorylation of the digested DNA and its ligation to adapter was performed according to Hamilton et al. (1999) without any modification. Adaptor ligated DNA was amplified in a PCR reaction using forward linker as primer. Electrophoresis of the PCR product on a $1.5 \%$ ethidium bromide stained agarose gel revealed a slight smear at 300 to $800 \mathrm{bp}$.

Microsatellite SEQUenCE ENRICHMENT. Adaptor ligated DNA (approximately $100 \mathrm{ng}$ ) was hybridized to $2 \mu \mathrm{L}(1 \mu \mathrm{M})$ repeat oligos $(\mathrm{CA})_{10},(\mathrm{CT})_{10}$ and $(\mathrm{CTT})_{8}$ with biotin label at the 5 '-end in 
a total volume of $100 \mu \mathrm{L}$ containing $30 \mu \mathrm{L} 20 \times$ SSC and $4.38 \mu \mathrm{L}$ forward linker ( $30 \mathrm{pmol})$. The reaction mixture was first denatured at $98^{\circ} \mathrm{C}$ for $15 \mathrm{~min}$. and then hybridized at $48^{\circ} \mathrm{C}$ for dinucleotide and $65^{\circ} \mathrm{C}$ for trinucleotide biotin labelled repeat oligos.

Fifty microliters of streptavidin coated magnesphere paramagnetic particles (Promega, Madison, Wis.) was resuspended and washed as recommended by the manufacturer. One-hundred microliters of the hybridization reaction was transferred to the tube containing magnetic particles and were incubated at $43^{\circ} \mathrm{C}$ for $1 \mathrm{~h}$. After incubation, magnetic beads were washed two times with $200 \mu \mathrm{L} 2 \times$ SSC, three times with $200 \mu \mathrm{L} 1 \times$ SSC and three times with $200 \mu \mathrm{L} 0.5 \times$ SSC. A final wash was done by shifting magnetic beads to a new tube and washing with $200 \mu 10.5 \times$ SSC solution. Each incubation after addition of SSC for washing was for $5 \mathrm{~min}$ at $48{ }^{\circ} \mathrm{C}$ for dinucleotide repeats and $60{ }^{\circ} \mathrm{C}$ for trinucleotide. A high power magnetic stand was used each time to separate magnetic beads and washing solution. After final washing, $30 \mu \mathrm{L}$ low TE buffer was added to the magnetic beads. After incubation at $98^{\circ} \mathrm{C}$ for $15 \mathrm{~min}$, the beads were quickly centrifuged for a few seconds, put on the magnetic stand and the bead free TE buffer was removed. This became elution 1 with sufficien microsatellite enriched DNA. The procedure was repeated with $60 \mu \mathrm{L}$ of TE buffer, which became elution 2. Next, $30 \mu \mathrm{L}$ TE buffer was added to the magnetic beads and they were stored at $-4{ }^{\circ} \mathrm{C}$ for future use.

PCR AMPLIFICATION OF CAPTURED FRAGMENTS AND THEIR CLONING. The captured DNA enriched for microsatellite was used as template by taking $3 \mu \mathrm{L}$ in a total volume of $50 \mu \mathrm{L}$ containing $250 \mathrm{nmol}$ forward linker as primer, $200 \mu \mathrm{M}$ of dNTPs, 1.5 to $2 \mathrm{~mm}$ $\mathrm{MgCl}_{2}, 1 \times$ PCR buffer (Qiagen), and 1U Taq DNA polymerase enzyme (Qiagen). The amplification was carried out for 35 cycles in an MJ thermal cycler with each cycle consisting of denaturing at $94{ }^{\circ} \mathrm{C}$ for $3 \mathrm{~min}$, annealing at $55^{\circ} \mathrm{C}$ for $1 \mathrm{~min}$ and extension at $72{ }^{\circ} \mathrm{C}$ for $2 \mathrm{~min}$. This was followed by a single extension at $72{ }^{\circ} \mathrm{C}$ for $7 \mathrm{~min}$. The PCR product was cleaned with Qia Quick Purification Column (Qiagen) and eluted into $30 \mu \mathrm{L}$ of double deionized $\mathrm{H}_{2} \mathrm{O}$. A light smear at the range of 300 to $800 \mathrm{bp}$ on $1.5 \%$ agarose gel stained with ethidium bromide showed recovery of DNA from the enrichment.

For more efficient transformation with the Topo TA cloning kit (Invitrogen, Carlsbad, Calif.), 1U Taq DNA polymerase, with dATP, $10 \times$ PCR buffer was added to the enriched DNA, incubated for $10 \mathrm{~min}$ and directly added to the pCR2.1 Topo cloning vector (Invitrogen) and chemically transformed the E. coli competent cells Top 10 (Invitrogen) according to the manufacturer's protocol. Cloned DNA insert size was determined by transfering white colonies to tubes containing $20 \mu \mathrm{L}$ of $10 \mathrm{~mm}$ Tris- $\mathrm{HCl} \mathrm{pH}$ 8.5 and incubating for $10 \mathrm{~min}$ at $95^{\circ} \mathrm{C}$. A total of $0.5 \mu \mathrm{L}$ of this lysate was used in a $20 \mu \mathrm{L}$ PCR amplification reaction with two M13 vector primers. Amplification products were visualized in agarose gel $(1.5 \%)$ stained with ethidium bromide.

Primer Selection ANd SSR LOCI AMPLIFICATION. Colonies having sufficient insert size were transfered to LB kanamycin freezing medium. Plasmids were isolated by plasmid mini kit (Qiagen). Sequencing was performed with an ABI 373 Auto Sequencer (Global Medical Instrumentation, Inc. Albestville, Minn.) using M13 (-21) as a forward primer. In some cases when the insert was long, resequencing was done by using M13 reverse primer. For each unique microsatellite that contained sufficient reliable flanking sequence, PCR primers were selected using the primer selection computer program Primer 3 (Steve and Skaletsky, 2000). The forward primers were labeled with IRD800 and IRD700 to be detected simultaneously on an automated DNA sequencer (LI-COR, Lincoln, Neb.).

PCR was carried out in a total volume of $12 \mu \mathrm{L}$ under the following conditions: 20 to $25 \mathrm{ng}$ of template DNA, $250 \mathrm{nmol}$ each primer, $200 \mu \mathrm{mol}$ dNTPs, 1U Taq DNA polymerase (Qiagen), 1.5 to $2 \mathrm{~mm} \mathrm{MgCl}_{2}, 1 \times \mathrm{PCR}$ buffer. The reaction, depending on the primer pair, was run for 35 to 45 cycles (denaturing at $94{ }^{\circ} \mathrm{C}$ for 1 minute, annealing at $55^{\circ} \mathrm{C}$ or $60{ }^{\circ} \mathrm{C}$ for $1 \mathrm{~min}$, with a 2 min extension at $72{ }^{\circ} \mathrm{C}$ ), followed by a single extension at $72{ }^{\circ} \mathrm{C}$ for $60 \mathrm{~min}$. The amplification products were detected on $5.5 \%$ polyacrylamide gels using a DNA sequencer (LI-COR). Gene Image IR analysis software (Scanalytics) was used for measuring allele size. Manual editing of the allele size was performed for more accuracy.

\section{Results and Discussion}

LIBRARY SCREENING AND SEQUENCE CHARACTERIZATION. Screening of nonenriched Lambda phage library with $(\mathrm{GA})_{10}$ and (GT) 10 probes identified 48 positive clones that were isolated and sequenced. Of those, $12(25 \%)$ contained dinucleotide repeats. Eighty percent of the clones having dinucleotide $(\mathrm{GA}) \mathrm{n}$ and (GT)n repeats were 10 to $20 \mathrm{bp}$ long. Only one clone had a compound sequence consisting of three classes of dinucleotide repeats of (GA)n, (AT)n and (GT)n. Primer pairs were designed for 10 clones having sufficient flanking sequences. After PCR amplification of Citrus DNA, seven primer pairs resulted in clean, interpretable products.

To increase the efficiency of isolation of more microsatellites in Citrus, we developed genomic libraries enriched for dinucleotide repeats $(\mathrm{CT} / \mathrm{GA}) \mathrm{n},(\mathrm{CA} / \mathrm{GT}) \mathrm{n}$ and trinucleotide repeats (CTT/GAA)n. In $80 \%$ of the clones, the insert size which was determined by PCR amplification ranged from 300 to $600 \mathrm{bp}$, facilitating later single pass sequencing. After sequencing of 31 clones from the (CT/GA)n enriched library, 18 (58\%) contained microsatellites of which three $(16.7 \%)$ were compound. From the (CA/GT)n enriched library, 35 clones were sequenced of which $28(80 \%)$ contained microsatellites. The number of compound microsatellites found in the sequenced clones from this library was $11(39 \%)$. The compound sequences consisted of classes of di, tri, and tetra-nucleotide repeats alternating with (CT)n and (CA)n repeats. Imperfect repeat sequences were relatively rare (around 6\%) for both libraries. In the (CT/GA)n enriched library, four $(22.2 \%)$ clones were redundant while in the $(\mathrm{CA} / \mathrm{GT}) \mathrm{n}$ library four $(14.2 \%)$ were redundant. In the (CT/GA)n enriched library, $94 \%$ of the clones having microsatellites had repeat lengths in the range of 10 to 30 units while only $6 \%$ had repeat lengths in the range of 30 to 50 units. For the (CA/GT)n library, $75 \%$ of the clones having microsatellites had repeat lengths of 10 to 30 units while the remaining $25 \%$ had $30-50$ repeats. In the 46 clones having a dinucleotide microsatellite, $31(67 \%)$ had sufficient flanking sequence for primer design. The rest of the clones were discarded for not having any microsatellite or the microsatellite was too small or the microsatellite was too close to the cloning site. From the 31 pairs of primers designed and tested with a single PCR program, 16 pairs amplified very clean and easily interpretable PCR products. For those primer pairs that have no amplification product or having a smear of bands, PCR conditions were optimized, but the results were unsatisfactory and were deleted from further evaluation.

From the library enriched for trinucleotide repeats (CTT/ GAA)n, we randomly selected 30 clones for sequencing from a 


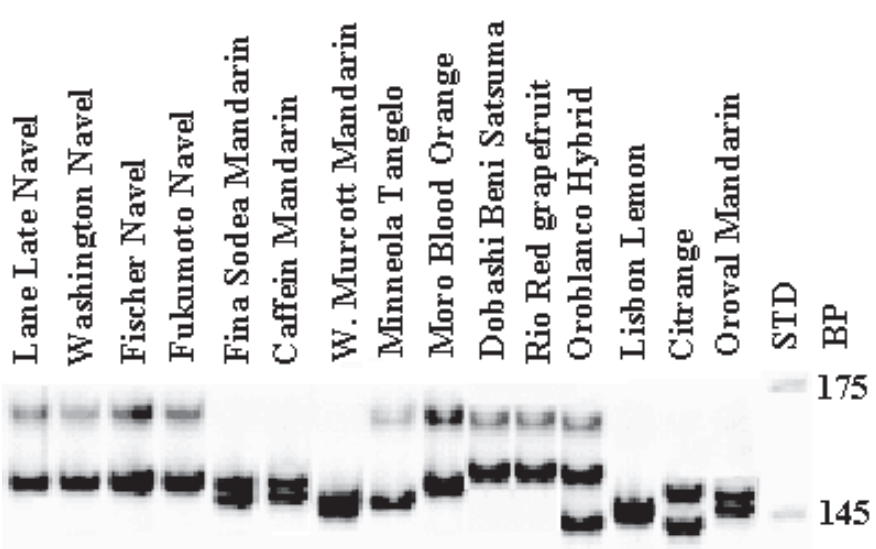

Fig. 1: Microsatellite polymorphism in 15 Citrus cultivars/clones representing different species, by the primer pair CMS-30. The IRD-labeled size marker (Li-Cor) at right side was used for measuring allele size.

total of 180 . Seven $(23 \%)$ clones had the trinucleotide microsatellite. Four primers were designed in which only three primer pairs produced the expected amplification product in citrus cultivars.

Our results showed that our enrichment protocol could be efficiently used for finding clones having microsatellites as compared to nonenriched procedures. We found on average $69.7 \%$ of the random set of clones sequenced from the libraries enriched for dinucleotide repeats contained microsatellites, in contrast to $25 \%$ from the nonenriched library. According to Thomas et al. (1998), $21 \%$ of clones from an enriched library developed in grapevine (Vitis vinifera L.) contained a microsatellite sequence. Butcher et al. (2000) observed that after an enrichment procedure $40 \%$ of colonies contained microsatellites in contrast to less than $1 \%$ from a nonenriched library in Acacia maggium. Szewe-Mcfadden et al. (1996) sequenced 141 clones in Brassica, in which 21 $(15 \%)$ primer pairs were designed and of these, 13 amplified polymorphism in a test array, resulting in an efficiency of $9.2 \%$ from sequencing to the production of operational loci. The method of Kijas et al. (1997) involves the construction of genomic libraries prior to the enrichment step and is therefore likely to be more time consuming. When compared to the enrichment protocol with post hybridization with isotope labeled probes of Van der Schoot et al. (2000), our enrichment protocol without post hybridization resulted in more microsatellite containing clones.

Our results indicated that trinucleotide copy number is lower than that of the dinucleotide repeats in the Citrus genome as observed by Kijas et al. (1995) and Thomas et al. (1998) in Citrus and Guilford et al. (1997) in apple. It was observed from both enriched and nonenriched libraries that both $\mathrm{CT}$ and CA repeats are abundant in the Citrus genome and can be used for marker development in citrus. Enrichment protocol captured more of the CA repeats than CT repeats. These results are in agreement with those of Butcher et al. (2000) for Acacia magginum and Van der Schoot et al. (2000) for Populus nigra L. and contrast with surveys in plants that have shown the most frequently occurring dinucleotide repeats to be (AT)n with (CT)n and (AC)n as second and third most frequent (Echt and May-Marquardt, 1997; Wang et al., 1994). The factors responsible for differences in the abundance of microsatellite motifs among plant genera are not well understood (Echt and May-Marquard, 1997). There is evidence that the repeat type and number is influenced by the restriction enzyme used to size fractionate the genome when constructing the library (Hamilton et al., 1999). We also observed more compound sequences in enriched libraries than in nonenriched libraries. In Citrus, the more common motif (CA)n also had the highest average repeat length as well as more compound microsatellites. This result is in agreement with that of Raffaele et al. (2000) for the peach (Prunuspersica L. Batsch) genome. Enrichment procedures which produce a high proportion of compound microsatellites may therefore also increase the probability of detecting CA repeats (Edwards et al., 1996). Condit and Hubble (1991) observed that $10 \%-20 \%$ of phage inserts that carried a CA repeat also carried a CT repeat, indicating a clustering of repeat regions. Non-random distribution and the clustering of CA repeats have also been proposed in Elymus caninus (Sun et al., 1998) and in wheat (Ma et al., 1996). We did not observe that GT/CA repeats were less polymorphic and difficult to score as observed by Taramino and Tingy (1996) in maize (Zea mays L) and Akkaya et al. (1992) in soybean (Glycine max).

On average $4 \%$ of redundant sequences were found in enriched libraries. This number will evidently increase when more clones are sequenced from the same enriched libraries. Brady et

Fig. 2: Amplification products of microsatellite CMS24 with 41 different Citrus cultivars/clones.

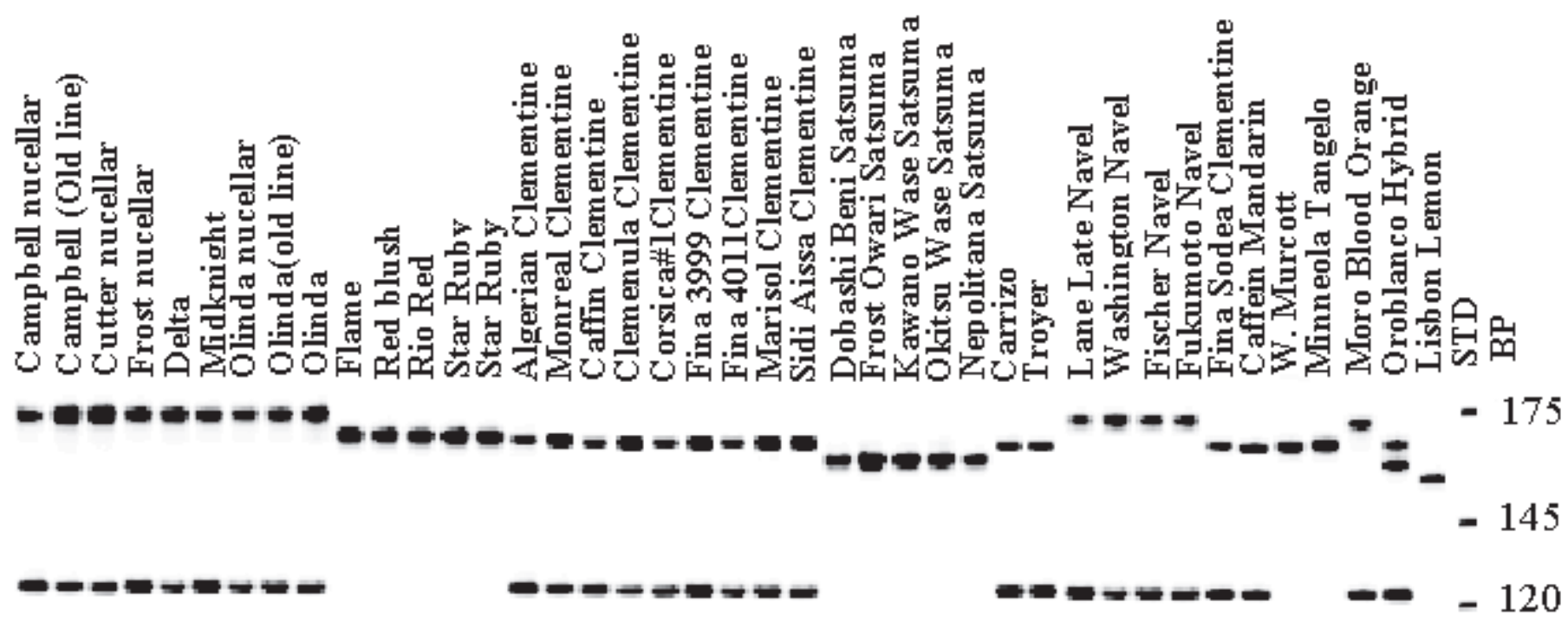


al. (1996) rejected $29 \%$ of the clones from an enriched library due to redundancy. Identical clones were not observed for the nonenriched library. Similarly, no redundant clones were found between the enriched and nonenriched libraries.

In contrast to the weak correlation between the number of alleles and the number of repeats as observed in wheat (Plaschke et al., 1995), and the stronger one in barley (Saghai Maroof et al., 1994), and peach (Raffaele et al., 2000), no correlation was detected for the 26 Citrus microsatellite in our study, in concordance with the results of Szewe-Mcfadden et al. (1996) in Brassica and Valdes et al. (1993) in humans.

Marker eValuation. The 26 microsatellite specific primer

Table2. Primer sequences, repeat motifs, number of putative alleles and their size revealed by 26 microsatellite in Citrus cultivars/clones.

\begin{tabular}{|c|c|c|c|c|c|c|}
\hline Primer & \multicolumn{2}{|c|}{$\begin{array}{l}\text { Sequence } \\
\left(5^{\prime}-3^{\prime}\right)\end{array}$} & \multirow{2}{*}{$\begin{array}{l}\text { Repeat } \\
\text { motif } \\
(\mathrm{CA}) 21\end{array}$} & \multirow{2}{*}{$\begin{array}{l}\text { No. of } \\
\text { loci }\end{array}$} & \multirow{2}{*}{$\begin{array}{l}\text { No. of } \\
\text { alleles }\end{array}$} & \multirow{2}{*}{$\begin{array}{l}\text { Allele } \\
\text { size (bp) } \\
90\end{array}$} \\
\hline CMS-2 & $\mathrm{F}$ & GACCAGCCTGGACAACATG & & & & \\
\hline & $\mathrm{R}$ & AATAGCTGGGACTGCAGGTG & & & & \\
\hline \multirow[t]{2}{*}{ CMS-3 } & $\mathrm{F}$ & ATCGATTTGATACCCCACTT & (CA) 17 & 1 & 2 & $125 / 142$ \\
\hline & $\mathrm{R}$ & TCTCTCCTTTGCTCCTTCCA & & & & \\
\hline \multirow[t]{2}{*}{ CMS-4 } & $\mathrm{F}$ & ССТСАААССТТСТТССААТСС & $(\mathrm{CT}) 11(\mathrm{AT}) 6(\mathrm{CA}) 6$ & 1 & 5 & $165 / 169 / 176 / 181 / 215$ \\
\hline & $\mathrm{R}$ & CTGTAAAGTACATGCATGTTGG & & & & \\
\hline \multirow[t]{2}{*}{ CMS-6 } & $\mathrm{F}$ & TATGGGCTAGCGCCGTAG & (AT) 14 & 1 & 3 & $98 / 103 / 109$ \\
\hline & $\mathrm{R}$ & TCCTCGTCTTTGGGTCGTAC & & & & \\
\hline \multirow[t]{2}{*}{ CMS-7 } & $\mathrm{F}$ & CAGGATGCTTGTTGGTGATG & $(\mathrm{CT}) 16$ & 2 & 4 & $144 / 149 / 151 / 154$ \\
\hline & $\mathrm{R}$ & ACAGTGGATACAAACATGCTGC & & & 3 & $335 / 344 / 355$ \\
\hline \multirow[t]{2}{*}{ CMS-8 } & $\mathrm{F}$ & CCAAACATCTGCGGATCC & (CT)11 & 1 & 2 & $140 / 148$ \\
\hline & $\mathrm{R}$ & AGAAGAACCCAGATTCCAAATG & & & & \\
\hline \multirow[t]{2}{*}{ CMS-10 } & $\mathrm{F}$ & TATGGTGGCAGATTAACAGCC & $(\mathrm{CT}) 10$ & 1 & 2 & $161 / 166$ \\
\hline & $\mathrm{R}$ & TACTCCGGAGAAAGATTTGGG & & & & \\
\hline \multirow[t]{2}{*}{ CMS-14 } & $\mathrm{F}$ & FGGCTTCTCTTCTACTAGAACGG & $(\mathrm{CA}) 14(\mathrm{GA}) 9$ & 1 & 5 & $132 / 156 / 162 / 171$ \\
\hline & $\mathrm{R}$ & ACGCCACGTAAGCAATAACC & & & & \\
\hline \multirow[t]{2}{*}{ CMS-16 } & $\mathrm{F}$ & AAAGAAAAATGTTATGTGCATG & (CA)21 & 2 & 3 & $159 / 167 / 169$ \\
\hline & $\mathrm{R}$ & GATGGAGTTTCTCTAGCTCCC & & & 2 & $285 / 287$ \\
\hline \multirow[t]{2}{*}{ CMS-17 } & $\mathrm{F}$ & CTGTGCTCTCAAAGCTCCG & (CT) 19 & 1 & 4 & $94 / 120 / 160 / 188$ \\
\hline & $\mathrm{R}$ & TCAGATTCAGAGTCAATGGAGG & & & & \\
\hline \multirow[t]{2}{*}{ CMS-18 } & $\mathrm{F}$ & GATGTCTTGATCCAGACTTC & $(\mathrm{CT}) 15$ & 1 & 3 & $85 / 120 / 145$ \\
\hline & $\mathrm{R}$ & CCAAGAGGAAGACTCAGACTCC & & & & \\
\hline \multirow[t]{2}{*}{ CMS-19 } & $\mathrm{F}$ & GGCTTTTGCCCAATGATG & (TCA)11(TC)14 & 1 & 5 & $146 / 157 / 159 / 161 / 164$ \\
\hline & $\mathrm{R}$ & GTTGACCTAAAAGGGGGGAG & & & & \\
\hline \multirow[t]{2}{*}{ CMS-20 } & $\mathrm{F}$ & GGAGCATATAAGCATAAACACC & (CA)13(AT)5 & 1 & 5 & $154 / 158 / 160 / 162 / 167 / 173$ \\
\hline & $\mathrm{R}$ & AGGAAAACGCATAAACCGTG & & & & \\
\hline \multirow[t]{2}{*}{ CMS-21 } & $\mathrm{F}$ & TAGGCCAAATCTTATTCATGCC & (CA) 10 & 1 & 3 & $120 / 138 / 145$ \\
\hline & $\mathrm{R}$ & TCAGGGTCATAAGGAATGGC & & & & \\
\hline \multirow[t]{2}{*}{ CMS-23 } & $\mathrm{F}$ & CTATGTGACAGCACTGATGG & (CA) 12 & 1 & 9 & $98 / 105 / 109 / / 118 / 120 / 124 / 126 / 130 / 145$ \\
\hline & $\mathrm{R}$ & TTTCСТATCTCTCTTGAGACAT & & & & \\
\hline CMS-24 & $\mathrm{F}$ & TTATTGTCCCCAATTGTGAGC & $(\mathrm{CA}) 20(\mathrm{TA}) 5$ & 1 & 5 & $123 / 152 / 157 / 164 / 169$ \\
\hline & $\mathrm{R}$ & TCCAGATTGAGGGGAAAAAG & & & & \\
\hline CMS-26 & $\mathrm{F}$ & TGATGTCTTGATCCACACTTCC & $(\mathrm{CT}) 16$ & 2 & 9 & $151 / 154 / 156 / 160 / 162 / 165 / 167 / 170 / 178$ \\
\hline & $\mathrm{R}$ & ACTCAAAGCTCCGCTACAGTG & & & 7 & $209 / 212 / 216 / 221 / 225 / 227 / 231$ \\
\hline CMS-30 & $\mathrm{F}$ & AACACCCCTTGGAGGGAG & $(\mathrm{CT}) 9(\mathrm{CA}) 5$ & 1 & 5 & $146 / 150 / 154 / 157 / 170$ \\
\hline & $\mathrm{R}$ & GCTGTTCACACACACAACCC & & & & \\
\hline CMS-31 & $\mathrm{F}$ & CGTGCAGAGAAACTCAGATCC & (CA) 10 & 1 & 4 & $156 / 158 / 162 / 169$ \\
\hline & $\mathrm{R}$ & GCTGAAAAAGATTCATTTTGCC & & & & \\
\hline CMS-33 & $\mathrm{F}$ & TCTGTCTGGATCTTGGTGGA & (CA) 10 & 1 & 2 & $120 / 135$ \\
\hline & $\mathrm{R}$ & GACTGAAAAGTGAAAACCGG & & & & \\
\hline CMS-34 & $\mathrm{F}$ & GCACTAAGCAGAATGCGTGT & (CA)39 (AT)11 & 1 & 3 & $155 / 160 / 165$ \\
\hline & $\mathrm{R}$ & GCCGTCGTTTTACATTCAAGA & & & & \\
\hline CMS-39 & $\mathrm{F}$ & CTCAGCTCTCTGTCTCTCCTCC & (CT)41 & 1 & 4 & $204 / 215 / 235 / 255$ \\
\hline & $\mathrm{R}$ & CTGGAGCAGGGTGACCTATC & & & & \\
\hline CMS-45 & $\mathrm{F}$ & CGACCACTCCACCTACGATG & $(\mathrm{CTT}) 7$ & 1 & 3 & $186 / 189 / 198$ \\
\hline & $\mathrm{R}$ & GCCGTTAATTCCTGCTTTCA & & & & \\
\hline CMS-46 & $\mathrm{F}$ & TCAAACATCAGACGAAGCAA & (A) 18 & 1 & 4 & $179 / 185 / 187 / 193$ \\
\hline & $\mathrm{R}$ & TGAATCTTTTGCCGAATTTTG & & & & \\
\hline CMS-47 & $\mathrm{F}$ & GGATCCTCCACCATCTCGTA & $(\mathrm{CTT}) 14$ & 2 & 5 & $162 / 167 / 171 / 173 / 175$ \\
\hline & $\mathrm{R}$ & TTCTTCTTCCATGCCGACTT & & & 3 & 186/191/194 \\
\hline CMS-48 & $\mathrm{F}$ & GTGGAGGAGAGGGAGAGGAG & (CTT) 8 & 1 & 4 & $105 / 110 / 115 / 118$ \\
\hline & $\mathrm{R}$ & CGAGATGCCAATTCAAATCA & & & & \\
\hline
\end{tabular}


pairs which resulted in a clear PCR product and amplified the expected target in Citrus cultivar Washington Navel were further tested for their efficiency in detecting polymorphism among 65 Citrus cultivars or clones representing different species. All primers except one CMS-2, revealed sufficient polymorphism. A total of 118 putative alleles were detected among the Citrus cultivars/clones with an average of 4.5 putative alleles per primer combination. The number of putative alleles per locus ranged from a minimum of one for CMS-2 to a maximum of nine for the most polymorphic marker CMS-26. No significant difference in polymorphism between CA/GT and CT/GA microsatellites and no correlation between the number of repeats of a microsatellite and the number of alleles detected within the tested Citrus cultivars/clones were observed. At all putative loci, microsatellites successfully amplified the target sequence across sweet oranges, grapefruit, mandarins, lemon and citranges.

Most microsatellites could very easily differentiate at the species level (Figs. 1 and 2), but individual cultivars within sweet oranges, grapefruit and mandarins, which are believed to have evolved by mutation, were not distinguishable. The maximum number of unique putative alleles were found in Lisbon lemon (11) followed by citranges (5) and Oroblanco (4). Primer sequences, repeat motif, number of putative alleles and their size in bp are shown in Table 2. Twenty-two primer pairs were single loci while four resulted in the amplification of two putative loci. Second putative loci were assigned only in those cases when another amplification product appeared consistently in the gel which was not in the expected size range for those primer combinations. For example, the amplification product produced by CMS-7 at 335-355 bp (Table 2) was considered as a second putative locus since it did not fall at the expected size for this primer which is $159 \mathrm{bp}$.

All microsatellites produced amplification products in the expected size range in all Citrus cultivars representing different species, which indicated that a high level of sequence conservation exists within the primer sites flanking the microsatellites in the Citrus genome. A large amount of structural and functional homology between Citrus genomes has been suggested in the past (Jarrell et al., 1992). According to Kijas et al. (1995), SSR primer conservation was found to exist across a broad range of Citrus and related species. For use in linkage mapping, microsatellites must be informative across many species and cultivars within the genus or family, especially where a wide range of genetic variability exist, as is the case within citrus.

No microsatellite was found to differentiate Navel oranges from Valencia. Only one microsatellite was able to separate Moro blood orange from sweet oranges. At all loci, no difference in the microsatellite profile was observed among samples of the 'Parent Washington Navel' collected from different sources as observed by Fang and Roose (1997) using ISSR markers. Similar results were obtained by Novelli et al. (2000) and Luro et al. (1995) in Citrus using different molecular markers. The origin of the different cultivars in sweet orange has been attributed to repeated interbreeding between pummello and mandarin (Sauer, 1994) or to somatic changes fixed by asexual reproduction (Barrett and Rhodes, 1976; Cameron and Frost, 1968). Some cultivars, such as Washington Navel, are known to have originated by mutation (Cameron and Soost, 1986; Hodgson, 1967). According to Hodgson (1967), nearly all commercially important sweet orange cultivars originated through mutations, which alter horticultural characters, mostly fruit traits. Fang and Roose (1997) observed that of 31 sweet orange cultivars, 14 differed from the basic ISSR profile by one to four of 1230 bands leading them to conclude that these differences originated by mutation. However, according to Moore (2001) it seems unusual that small mutations as observed by Fang and Roose (1997) could be revealed at such a frequency using molecular markers.

Mandarin cultivars within the Satsuma and Clementine groups are differentiated from each other mainly in the time of harvest and fruit shape (Davies and Albrigo, 1994). In our results, Clementine mandarins were distinguished by 34,23 , and 20 microsatellite fragments when compared to Satsumas, W. Murcot mandarin, and Minneola tangelo, respectively. Similarly, Satsuma were identified by 34 markers from Oroval mandarin, 21 from W. Murcot mandarin, and 22 from Minneola tangelo. According to Breto et al. (2001), genetic variability within Clementine mandarins is minimal when analyzed by molecular markers because existing varieties like sweet orange and Satsuma mandarins have not been obtained through hybridization, but through the selection of spontaneous mutations affecting traits of horticultural interest. Fang and Roose (1997) observed that the five mutationally derived Satsuma cultivars were identical to one another as observed in our results. Similarly, no variation was detected in six grapefruit cultivars, which are believed to originate by mutation from the same ancestral tree. However, 19 markers were found to differentiate grapefruit from 'Oroblanco' which is a triploid hybrid of pummelo (C.maxima) and grapefruit and displays three microsatellite alleles with several primer pairs (Fig. 1 and 2) .

This study reveals the abundance of microsatellites in the Citrus genome. We isolated more microsatellites from an enriched library than a nonenriched library without post hybridization or use of radioisotopes. Our results showed conservation of microsatellite loci among the most important Citrus species. Microsatellites were able to efficiently identify cultivars at the species level, but individual cultivars within each species, believed to have evolved through mutation, were undistinguishable. Consequently, like other genetic markers, it seems that primer amplified microsatellite loci are not useful for the detection of point mutations (Breto et al., 2001).

\section{Literature Cited}

Akkaya, M.S., A.A. Bhagwat, and P.B. Cregan. 1992. Length polymorphisms of simple sequence repeat DNA in soybean. Genetics 132: 1131-1139.

Barrett, H.C. and A.M. Rhodes. 1976. A numerical taxonomic study of affinity relationship in cultivated Citrus and its close relatives. Syst. Bot. 1:105-136.

Breto, M.P., C. Ruiz, J. A. Pina, and M.J. Asin. 2001. The diversification of Citrus clementina.

Hort. Extan. A vegetatively propagated crop species, p. 285-293. In Molecular phylogenetics and evolution. vol. 21.

Brady, J.L., N.S. Scott, and M.R. Thomas. 1996. DNA typing of hops (Humulas lupulus) through application of RAPD and microsatellite marker sequences conserved to sequence tagged sites (STS). Euphytica 91:277-284

Butcher,P.A., S. Decroocq, Y. Gray, and G.F. Moran. 2000. Development, inheritance and cross-species amplification of microsatellite markers from Acacia maggium. Theor.Appl. Genet. 101:1282-1290.

Cameron, J.W. and R.K. Soost. 1986. Citrus, p. 261-265. In: N.W. Simmonds (ed.). Evolution of crop plants. Longman Scientific and Technical, Essex.

Cameron, J.W. and H.B. Frost. 1968. Genetics, breeding and nucellar embryony, p. 325-389. In:W. Reuther,L.D. Batchelor, and H.D. Webber (eds.). The citrus industry. vol. 2. Univ. Calif. Press, Berkeley.

Coletta Filho, H.D., M.A. Machado, M.L.P.N. Targon., M.C.P.Q.D.G. Moreira, and J. Pompeu, Jr. 1998. Analysis of the genetic diversity 
among mandarins (Citrus spp.) using RAPD markers. Euphytica 102: 133-139.

Conditt, R. and S.P. Hubble. 1991. Abundance and DNA sequence of two-base repeat regions in tropical tree genomes. Genome 34:66-71.

Davies, F.S. and L.G. Albrigo. 1994. Taxonomy, cultivars and breeding, p. 15-52. In: F.S. Davies and L.G. Albrigo (eds.). Citrus. CAB Intl., Wallingford.

Edwards, K.J., J.H.A. Barker, A. Daly, C. Jones, and A. Karp. 1996. Microsatellite libraries enriched for several microsatellite sequences in plants. Biotechnology 20:759-760.

Echt, C.S. and P. May-Marquardt. 1997. Survey of microsatellite DNA in pine. Genome 40:9-17.

Fang, D.Q. and M.L. Roose. 1997. Identification of closely related citrus cultivars with inter-simple sequence repeat markers. Theor. Appl. Genet. 95:408-417.

Federici,C.T., D.Q. Fang, R.W. Scorza, and M.L. Roose. 1998. Phylogenetic relationships within the genus Citrus (Rutaceae) and related genera as revealed by RFLP and RAPD analysis. Theor. Appl. Genet. 96:812-822.

Feinberg, A.P. and B. Vogelstein. 1983. A technique for radiolabelling DNA restriction fragments to high specific activity. Anal. Biochem. 132:6-13.

Guilford, P., S. Prakash, J.M. Zhu, E. Rikkerink, S. Gardiner, H. Bassett, and R. Forster. 1997. Microsatellite in Malus $\times$ domestica (apple) Abundance, polymorphism and cultivar identification. Theor. Appl. Genet. 94:245-249.

Hamilton, M.B., E.L. Pincus, A.D. Fiore, and R.C. Fleischer. 1999. Universal linker and ligation procedure for construction of genomic DNA libraries enriched for microsatellites. Biotechnology 27:500-507.

Haymer, D.S. 1994. Random Amplified Polymorphic DNAs and microsatellites: what are they, and can they tell us anything we don't already know? Ann. Entomol. Soc. Amer. 87:717-722.

Hodgson, R.W. 1967. Horticultural varieties of citrus, p. 431-591. In: W. Reuther, H.J. Webber, and L.D. Batchelor (eds.). The citrus industry. vol. 1. Univ. Calif. Press, Berkeley.

Jarrell, D.C., M.L. Roose, S.N. Traugh, and R.S. Kupper. 1992. Agenetic map of citrus based on the segregation of isozymes and RFLPs in an intergeneric cross. Theor. Appl. Genet. 84:49-56.

Kijas, J.M.H., J.C.S. Fowler, and M.R. Thomas. 1995. An evaluation of sequence tagged microsatellite site markers for genetic analysis within Citrus and related species. Genome 38:349-355.

Kijas, J.M.H., M.R. Thomas, J.C.S. Fowler, and M.L. Roose. 1997. Integration of trinucleotide microsatellites into a linkage map of Citrus. Theor. Appl. Genet. 94:701-706.

Ling P., L.W. Duncan, Z. Deng, D. Dunn, X. Hu, S. Huang, and F.G Gmitter, Jr. 2000. Inheritance of citrus nematode resistance and its linkage with molecular markers. Theor. Appl. Genet. 100:1010-1017.

Luro, F., F. Laigret, J.M. Bove, and P. Ollitraut. 1995. DNA amplified fingerprinting, a useful tool for determination of genetic origin and diversity analysis in Citrus. HortScience 30:1063-1067.

Ma,Z.Q., M.S. Roder, and M.E. Sorrells. 1996. Frequencies and sequence characteristic of di-, tri- and tetra- nucleotide microsatellites in wheat Genome 39:123-130.

Moore, G.A. 2001. Oranges and lemons. Clues to the taxonomy of Citrus from molecular markers. TRENDS in Genetics. 17:536-540.
Novelli, V. M., M. Cristofani, and M.A. Machado. 2000. Evaluation of microsatellite markers in cultivars of sweet orange. Acta Hort. 535: 47-50.

Plaschke, J., M.W. Ganel, and M.S. Roder. 1995. Detection of genetic diversity in closely related bread wheat using microsatellite markers. Theor. Appl. Genet. 91:1001-1007.

Raffaele, T., T. Marrazzo, G. Cipriani, R. Quarta, I. Verde, M.T. Dettori, M. Pancalli, and S. Sansavini. 2000. Microsatellite DNA in peach [Prunus persica (L.) Batsch] and its use in fingerprinting and testing the genetic origin of cultivars. Genome 43:512-520.

Saghai Maroof, M.A., R.M. Biyashev, G.P. Yang, Q. Zang, and R.W. Allard. 1994. Extraordinarily polymorphic microsatellite DNA in barley: Species diversity, chromosomal locations, and population dynamics. Proc. Natl. Acad. Sci. USA 91:5466-5670.

Sauer, J.D. 1994. Rutaceae-Citrus family. In: Historical geography of crop plants: A select poster. CRC, EUA.

Smith, D. and M. Devey. 1994. Occurrence and inheritance of microsatellites in Pinus radiata. Genome 37:977-983.

Smulders, M.J.M., G. Bredemeijer, W. Rus-Kortekaas, P. Arens, and B. Vosman. 1997. Use of short microsatellites from database sequences to generate polymorphisms among Lycopersicon esculentum cultivars and accessions of other Lycopersicon species. Theor. Appl. Genet. 97: 264-272.

Spiegel-Roy, P. and E.E. Goldschmidt. 1996. Biology of citrus. Cambridge Univ. Press., Cambridge.

Steve, R. and J. H. Skaletsky. 2000. Primer3 on the WWW for general users and for biologist programmers, p. 365-386. In: S. Krawetz and S. Misener (eds.). Bioinformatics methods and protocols: Methods in molecular biology. Humana Press, Totowa, N.J.

Struss, D. and J. Plieske. 1998. The use of microsatellite markers for detection of genetic diversity in barley populations. Theor. Appl. Genet. 97:308-315.

Sun, G.L., B. Salomon, and R.V. Bothmer. 1998. Characterization and analysis of microsatellite loci in Elymus caninus (Triticeae: Poaceae). Theor. Appl. Genet. 96:676-682.

Szwec-McFadden, A.K., S. Kresovich, S.M. Bliek, S.E. Mitchell, and J.R. McFerson. 1996. Identification of polymorphic, conserved simple sequence repeats (SSRs) in cultivated Brassica species. Theor. Appl. Genet. 93:534-538.

Taramino, G. and S.Tingey. 1996. Simple sequence repeats for germplasm analysis and mapping in maize. Genome 39:277-287.

Thomas, M.R., N.S. Scott, R. Botta, and J.M.H. Kijas. 1998. Sequencetagged site markers in grape vine and citrus. J. Jpn. Soc. Hort. Sci. 67:1189-1192.

Valdes, A.M., M. Slatkin, and N.B. Freimer. 1993. Allele frequencies of microsatellite loci: the stepwise mutation model revised. Genetics 133:737-749.

Van der Schoot, J., M. Pospiskova, B. Vosman, and M.J.M. Smulders. 2000. Development and characterization of microsatellite markers in black poplar (Populus nigra L.) Theor. Appl. Genet. 101:317-322.

Wang, Z., J.L. Weber, G. Zhong, and S.D. Tanksley. 1994. Survey of plant short tandem DNA repeats. Theor. Appl. Genet. 88:1-6.

$\mathrm{Wu}$, K.S. and S.D. Tanksley. 1993. Abundance, polymorphism and genetic mapping of microsatellites in rice. Mol. Gen. Genet. 241:225-235. 